\title{
Pooled analysis of the reports of carfilzomib, panobinostat, and elotuzumab combinations in patients with refractory/ relapsed multiple myeloma
}

\author{
Liping Liu', Ningning Zhao ${ }^{1}$, Wenjun $\mathrm{Xu}^{1}$, Zhixin Sheng ${ }^{1}$ and Lida Wang ${ }^{2 *}$
}

\begin{abstract}
Purpose: The purpose of this study was to better understand the efficacy and safety of carfilzomib, panobinostat, and elotuzumab combinations in patients with refractory/relapsed multiple myeloma(R/RMM).

Methods: We retrieved and reviewed published reports including carfilzomib, panobinostat, and elotuzumab combination regimens for patients with R/RMM.

Results: We identified 20 prospective studies that evaluated 2220 patients. Carfilzomib combination regimens produced an overall response rate (ORR $\geq P R)$ of $61 \%$ in the 1211 relapsed/refractory patients. At least very good partial response (VGPR) was $29 \%$ in patients with carfilzomib combinations. Finally, $49 \%$ of the 597 patients achieved ORR in patients receiving panobinostat-containing combinations. At least VGPR was $16 \%$ in patients with panobinostat combinations. Three hundred twenty-eight of these 449 patients (73 \%) receiving elotuzumabcontaining combinations achieved ORR. And at least VGPR was $37 \%$. And, the vital nonhematologic adverse events (AEs) were cardiac events and pneumonia.
\end{abstract}

Conclusion: Carfilzomib, panobinostat, and elotuzumab combination regimens produced clinical benefits in patients with $\mathrm{R} / \mathrm{RMM}$.

Keywords: Carfilzomib, Panobinostat, Elotuzumab, Multiple myeloma

Abbreviations: R/RMM, Refractory/relapsed multiple myeloma; ORR, Overall response rate; VGPR, Very good partial response rate; CBR, Clinical benefit rate; SDR, Stable disease rate; PDR, Progressive disease rate; CFZ, Carfilzomib; PAN, Panobinostat; ELO, Elotuzumab; DEX, Dexamethasone; BOR, Bortezomib; LEN, Lenalidomide

\section{To the editor}

Relapsed myeloma disease is characterized by increasingly lower remission rate even following salvage therapy [1]. So, there is still an urgent need for new treatments to improve the outcomes of such patients. Carfilzomib (CFZ; a selective proteasome inhibitor), panobinostat (PAN; a pan-deacetylase inhibitor), and elotuzumab (ELO; a fully humanized monoclonal antibody against CS1 with significant anti-myeloma activity) are potent anti-myeloma agents with different mechanisms of action [2-4]. We conducted a pooled analysis to determine the efficacy and safety of

* Correspondence: 452697850@qq.com

2E.N.T. Department, Weifang People's Hospital, Weifang, China

Full list of author information is available at the end of the article carfilzomib, panobinostat, and elotuzumab combination regimens in these patients with relapsed/refractory multiple myeloma (R/RMM). The primary outcomes of the analysis were the overall response rate $(O R R \geq P R)$, at least very good partial response (VGPR), clinical benefit rate $(C B R \geq M R)$, stable disease rate (SDR), and progressive disease rate (PDR). Statistical analysis method has been shown in Appendix 1.

We identified 20 prospective studies that evaluated 2220 patients with R/RMM receiving carfilzomib-, panobinostat-, or elotuzumab-containing combinations [5-24]. Table 1 summarizes the characteristics of 20 identified clinical reports. As shown in Fig. 1a, 351 of 1211 response-evaluable R/RMM patients $(29 \%)$ who received carfilzomib 
Table 1 Characteristics of included studies

\begin{tabular}{|c|c|c|c|c|c|c|c|c|c|c|c|c|c|}
\hline \multirow{2}{*}{$\begin{array}{l}\text { Author, year } \\
\text { Strategy }\end{array}$} & \multirow{2}{*}{$\begin{array}{l}\text { Age } \\
\text { Median }\end{array}$} & \multirow{2}{*}{$\begin{array}{l}F / M \\
(n / N)\end{array}$} & \multirow{2}{*}{$\begin{array}{l}\text { TFD (Y) } \\
\text { Median }\end{array}$} & \multirow{2}{*}{$\begin{array}{l}\text { Cytogenetic } \\
\text { F/U/M }\end{array}$} & \multirow{2}{*}{$\begin{array}{l}\text { Drug dose } \\
\mathrm{mg} / \mathrm{m}^{2}\end{array}$} & \multirow{2}{*}{$\begin{array}{l}\text { Prior } \\
\text { therapy } \\
\text { median }\end{array}$} & \multicolumn{2}{|c|}{ Prior therapy } & \multirow[t]{2}{*}{ Regimen } & \multirow[t]{2}{*}{ ORR } & \multirow{2}{*}{$\begin{array}{l}\text { PFS } \\
(\mathrm{m})\end{array}$} & \multirow{2}{*}{$\begin{array}{l}\text { OS } \\
(\mathrm{m})\end{array}$} & \multirow{2}{*}{$\begin{array}{l}\text { Study } \\
\text { design }\end{array}$} \\
\hline & & & & & & & Bort & Lena & & & & & \\
\hline \multicolumn{14}{|c|}{ Carfilzomib combinations for R/RMM } \\
\hline Berdeja 2015 [5] & 66 & $27 / 17$ & - & - & 20/27/36/45 & $5(1-10)$ & - & - & $\mathrm{CP}$ & 0.67 & 7.7 & - & Phase $|/| \mid$ \\
\hline Shan 2015 [6] & 64 & $12 / 20$ & 5.9 & $10 /-/-$ & $20 / 27 / 36 / 45 / 56$ & $6(2-12)$ & 31 & 32 & CPD & 0.50 & 7.2 & 20.6 & Phase I \\
\hline Berenson 2014(1) [7] & 67 & $13 / 25$ & 4.2 & - & 20/27/36/45 & - & - & - & $\triangleright$ & 0.43 & 9.9 & 15.8 & Phase $|/| \mid$ \\
\hline Niesvizky 2013 [8] & 61.5 & $18 / 22$ & 3.3 & $25 / 11 / 4$ & $15 / 20 / 27$ & $2(1-3)$ & 30 & 28 & CRD & 0.62 & 10.2 & - & Phase lb \\
\hline Papadopoulos 2015 [9] & 59.5 & $5 / 17$ & 3.6 & $14 / 7 / 1$ & 20/36/45/56/70 & $4(2-9)$ & 21 & - & $C D$ & 0.55 & - & - & Phase I \\
\hline Stewart 2015 [10] & 64.0 & $181 / 215$ & 3.0 & 48/147/201 & $20 / 27$ & $2(1-3)$ & 261 & 79 & CRD & 0.87 & 26.3 & - & phase $|/| \mid$ \\
\hline Wang 2013 [11] & 61.5 & $36 / 48$ & 3.1 & $57 / 22 / 5$ & $20 / 27$ & $2(1-5)$ & 65 & 59 & CRD & 0.69 & 11.8 & - & Phase II \\
\hline Berenson 2014 (2) [12] & 63 & - & - & - & 20/45/56/70/88 & $1(1-2)$ & - & - & $C D$ & 0.67 & - & - & Phase I/II \\
\hline Dimopoulos 2015 [13] & - & - & - & - & $20 / 56$ & - & - & - & $C D$ & 0.77 & - & - & Phase III \\
\hline Kaufman 2014 [14] & 64.5 & - & - & - & $20 / 36 / 45$ & - & - & - & $C P$ & 0.50 & 14.3 & - & Phase I \\
\hline Vesole 2015 [15] & 61 & $7 / 10$ & 4 & $3 / 12 / 2$ & $15 / 20 / 27$ & $4(1-9)$ & 17 & 16 & QUAD & 0.53 & 12 & - & Phase I \\
\hline \multicolumn{14}{|c|}{ Panobinostat combinations for R/RMM } \\
\hline \multirow[t]{2}{*}{ Offidani 2012 [16] } & 73 & $5 / 7$ & - & - & 15 & - & 8 & 5 & PMT & 0.41 & 14.3 & - & Phase II \\
\hline & 65 & $10 / 9$ & - & - & 10 & - & 16 & 9 & PMT & 0.37 & 14.3 & - & Phase II \\
\hline Richardson 2013 [17] & 61 & $26 / 29$ & 4.6 & 2/35/18 & & $4(2-11)$ & 55 & 54 & PBD & 0.34 & 5.4 & - & Phase II \\
\hline San-Miguel 2013 [18] & 62 & $19 / 43$ & - & - & $10 / 20 / 25 / 30$ & $2(1-10)$ & 39 & 28 & PBD & 0.52 & - & - & Phase Ib \\
\hline Kaufman 2014 [14] & 64.5 & - & - & - & $15-20$ & - & - & - & $C P$ & 0.50 & 14.3 & - & Phase I \\
\hline Berenson 2014 [19] & 65 & $15 / 25$ & - & - & 20 & $4(1-16)$ & - & - & PM & 0.07 & - & - & Phase I/II \\
\hline San-Miguel 2014 [20] & 63 & $185 / 202$ & - & - & 20 & - & 169 & 72 & PBD & 0.61 & $11 \cdot 99$ & $33 \cdot 6$ & Phase III \\
\hline Berdeja 2015 [5] & 66 & $27 / 17$ & - & - & $20 / 30$ & $5(1-10)$ & - & - & $\mathrm{CP}$ & 0.67 & 7.7 & & Phase I/II \\
\hline \multicolumn{14}{|c|}{ Elotuzumab combinations for R/RMM } \\
\hline Jakubowiak 2012 [21] & 63 & $20 / 18$ & 3.5 & - & 2.5/4.0/10/20 & $2(1-3)$ & 11 & 13 & EB & 0.48 & 9.46 & - & Phase I \\
\hline Ionial 2012 [22] & 60 & - & 5.2 & $26 / 3 / 0$ & $2.5 / 10 / 20$ & $3(1-10)$ & 20 & 6 & ERD & 0.82 & & - & Phase I \\
\hline Ionial 2015 [23] & 67 & - & - & - & 10 & $2(1-4)$ & 219 & 16 & ERD & 0.79 & 19.4 & - & Phase III \\
\hline \multirow[t]{2}{*}{ Richardson 2015 [24] } & 60.6 & $17 / 19$ & 4.76 & $32 / 1 / 3$ & 10 & - & 22 & - & ERD & 0.92 & $32 \cdot 49$ & - & Phase Ib-\|ll \\
\hline & 63.3 & $13 / 24$ & 4.96 & $27 / 3 / 7$ & 20 & - & 22 & - & ERD & 0.76 & $25 \cdot 00$ & - & Phase Ib-II \\
\hline
\end{tabular}

Abbreviations: $F$ female; $M$ male; TFD time from diagnosis; F/U/M favor/unfavor/miss; CFZ carfilzomib; Bor bortezomib; Lena lenalidomide; CPD carfilzomib, pomalidomide, and dexamethasone; Replacement of bortezomib with carfilzomib from bortezomib combination therapy, $C D$ carfilzomib, dexamethasone; $C R D$ Carfilzomib, lenalidomide, and dexamethasone; $C P$ carfilzomib, panobinostat; $C C D$ carfilzomib, cyclophosphamide, and dexamethasone; $Q U A D$ carfilzomib, lenalidomide, vorinostat, and dexamethasone; PMT panobinostat melphalan prednisone; PBD panobinostat, bortezomib, and dexamethasone; $E B$ elotuzumab bortezomib, ERD elotuzumab, lenalidomide, and dexamethasone

combination therapy in 12 trials achieved at least a VGPR, and 739 patients $(61 \%)$ achieved OR. And 727 patients were evaluable for CBR analysis, and CBR was $74 \%$. And subgroup analysis indicated that the combination of carfilzomib and dexamethasone (DEX) achieved an ORR of $83 \%$, at least VGPR of $49 \%$, in those 533 response evaluable patients; in those 520 response evaluable patients, the ORR of 89 \% derived from CRD (CFZ/LEN/DEX) compares favorably with that of $66.7 \%$ from RD (LEN/DEX) [10]. Furthermore, the addition of carfilzomib to lenalidomide (LEN) and dexamethasone could improve progression free survival by $31 \%$ [10].

Sensitivity analyses shown that the combination of panobinostat and melphalan regimen [19] differed much from the others, which contribute most to the heterogeneity. In order to strengthen the reliability of this pooled analysis, we exclude this trial. When excluding this trial, as shown in Fig. 1b, 49 \% of the 597 evaluable R/RMM patients treated with panobinostat-containing combination regimens achieved an ORR, at least VGPR was achieved by $16 \%$, CBR by $66 \%$, the SDR was $28 \%$, and the PDR was $17 \%$. In those 504 response evaluable patients, the ORR of $48 \%$ derived from PBD (PAN/ $\mathrm{BOR} / \mathrm{DEX}$ ) regimen seems to be higher than that of bortezomib (BOR)-containing therapy in a similar population [25]. Furthermore, the addition of panobinostat to bortezomib and dexamethasone could reduce the risk of disease progression by $37 \%$ [20]. 
a

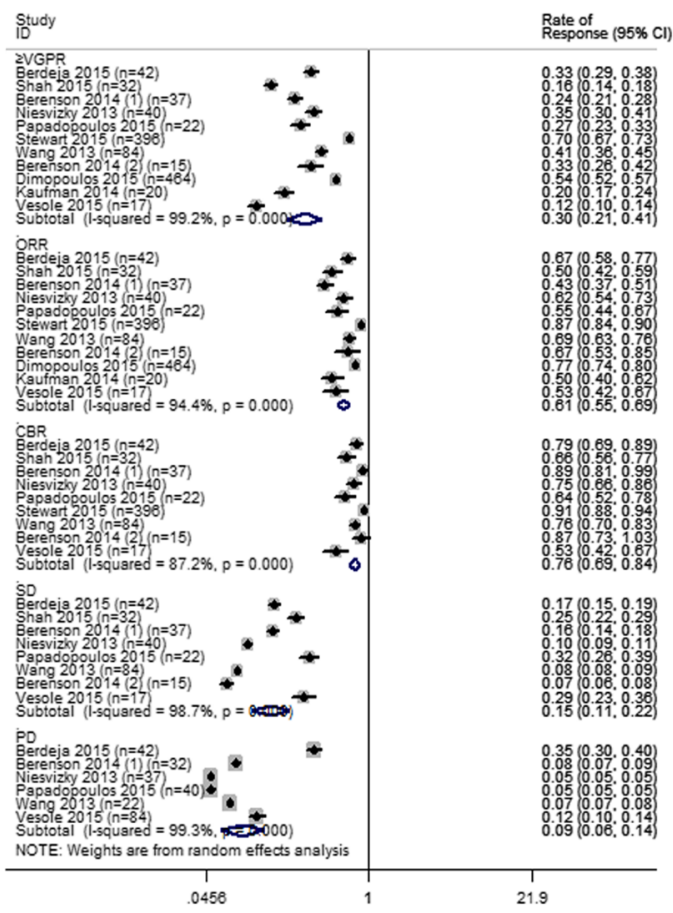

b Stud

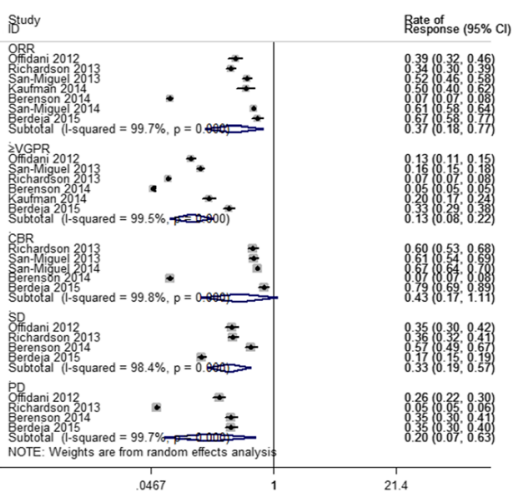

C

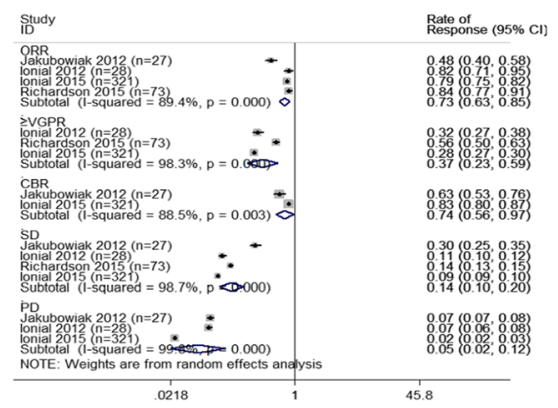

Fig. 1 Meta-analysis of the response rate of carfilzomib (a), panobinostat (b), and elotuzumab (c) combination regimens in patients with relapsed and refractory multiple myeloma. $n$ number of the enrolled patients, Cl $95 \%$ confidence interval, Random random effects model

As shown in Fig. 1c, four trials enrolling a total of 449 patients evaluated the response rate of elotuzumabcontaining combination regimens for those patients with R/RMM. Three hundred twenty-eight of 449 patients (73 \%) achieved ORR. And at least VGPR was $37 \%$, and CBR was $74 \%$. In the 422 response evaluable patients, the ORRs of $80 \%$ derived from ERD (ELO/ LEN/DEX) was encouraging, which compared favorably with that of 60 to $61 \%$ reported in the two trials of RD (LEN/DEX) [26, 27].

In the pooled analysis, the most common adverse events (AEs) consisted primarily of myelosuppression (Fig. 2). And the vital nonhematologic AEs were cardiac events and pneumonia (Fig. 3). Notably, neuropathy was generally mild and infrequent in most carfilzomib trials. But $1 \%$ of 589 patients with baseline grade $1-2$ peripheral neuropathy increased to grade 3 before resolving.

When interpreting our results, there are some limitations that should be considered. The first and major problem is that we used abstracted data. A meta-analysis of individual patient data might more clearly define the treatment benefits of these agents and allow time-toevent analyses of progression-free and overall survival. Secondly, as is often the case with meta-analysis, the effect of heterogeneity needs to be taken into account. Finally, the quality of a meta-analysis is always subject to the quality of included studies. Eighteen of the 20 trials included in this pooled analysis were no-RCTs. And, three of them reported interim analyses, and it is unclear whether these results would change when their final analyses are conducted.

In conclusion, the results presented here show that carfilzomib, panobinostat, and elotuzumab combination regimens produced clinical benefits in patients with $\mathrm{R} /$ RMM and had acceptable safety profile.

\section{Appendix 1 \\ Methods}

\section{Literature search strategy}

Medline, Embase, the Cochrane controlled trials register, the Science Citation Index, Conference proceedings from the American Society of Hematology(ASH), the European Hematology association (EHA) and the American Society of Clinical Oncology were searched for prospective trials using the medical subject headings "myeloma," "carfilzomib," "panobinostat," and "elotuzumab." Reference lists from studies selected for this review and from other published systematic reviews and practice guidelines were also hand-searched.

\section{Selection of studies}

Studies were eligible for inclusion in the meta-analysis if they met all the following criteria: (1) they were published 
a

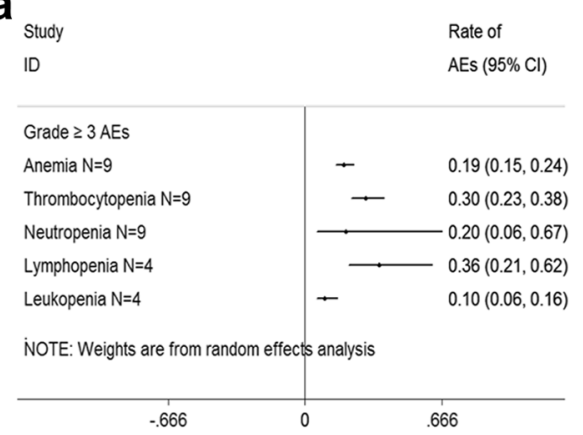

$\mathbf{C}_{\text {Study }}$

ID

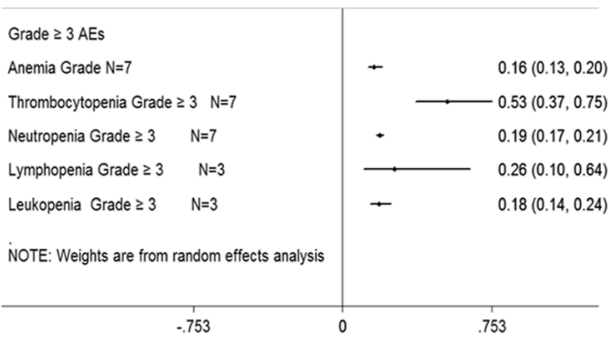

$\mathbf{e}_{\text {study }}$

ID

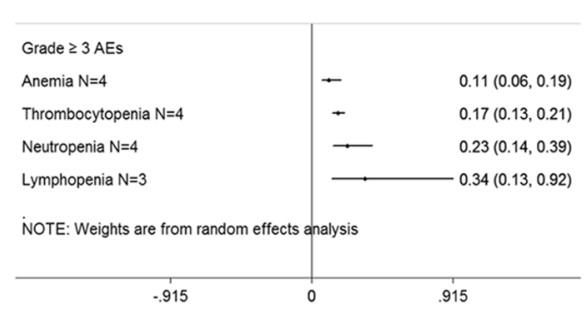

b

f

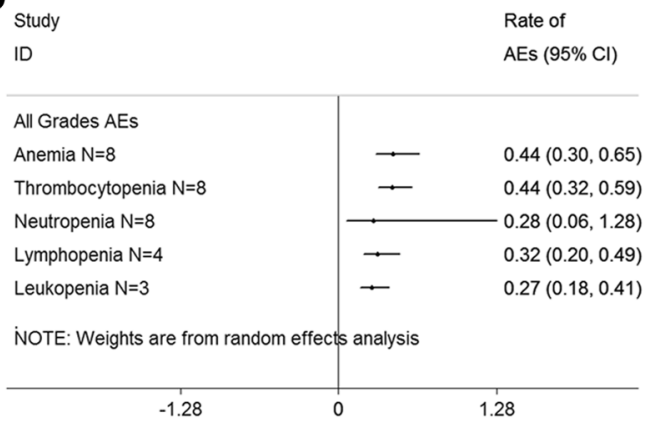

$\mathbf{d}_{\text {suod }}$ ID

Rate of AEs $(95 \% \mathrm{Cl})$
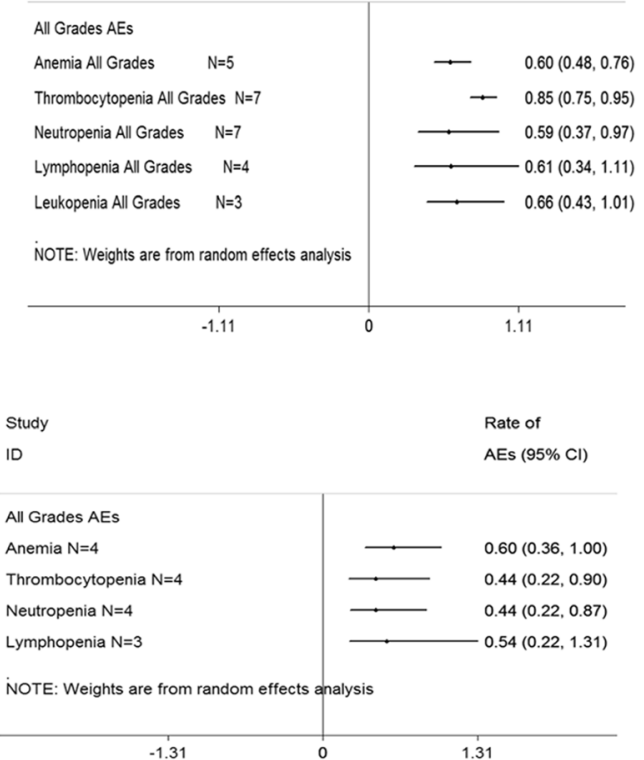

Fig. 2 Meta-analysis of hematologic adverse events (AEs) with variable carfilzomib/panobinostat/elotuzumab-containing combination regimens in patients with multiple myeloma. $\mathbf{a} \geq$ Grade 3 hematologic AEs with carfilzomib combination regimens in patients with relapsed and refractory multiple myeloma. b All grades hematologic AEs with carfilzomib combination regimens in patients with relapsed and refractory multiple myeloma. c $\geq$ Grade 3 hematologic AEs with panobinostat combination regimens in patients with relapsed and refractory multiple myeloma. $\mathbf{d}$ All grades hematologic AEs panobinostat combination regimens in patients with relapsed and refractory multiple myeloma. e $\geq$ Grade 3 hematologic AEs with elotuzumab combination regimens in patients with relapsed and refractory multiple myeloma. $\mathbf{f}$ All grades hematologic AEs with elotuzumab combination regimens in patients with relapsed and refractory multiple myeloma. N number of the included trials, Cl $95 \%$ confidence interval, Random random effects model

up to February, 2016, and written in English, (2) they dealt only with patients with refractory or relapsed multiple myeloma, (3) study selection included the setting of these trials: carfilzomib, panobinostat, and elotuzumab combinations, and (4) we included studies that provided sufficient information to allow the calculation of response rate. Multiple reports of a single study were considered as one publication, and only the most recent or complete article was examined. All potentially relevant articles were reviewed by two independent investigators (L.D.W and L.P.L).

\section{Statistical analysis}

All analyses were conducted using a random effects model, which could give a more conservative evaluation of treatment effect. The heterogeneity of between-study and between-subgroup were tested using the Cochrane $\chi^{2}$ test. We also undertook subgroup analyses to seek the source of heterogeneity. We used a visual inspection of the funnel plot and trim and fill analyses to evaluate the influence of publication bias on the pooled RR. All meta-analyses were conducted with Stata ver.12.0 software and Review Manager version 5.1. 
a

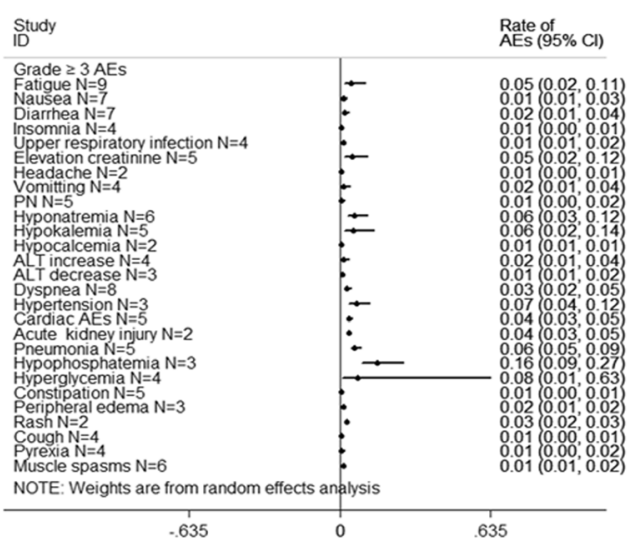

C

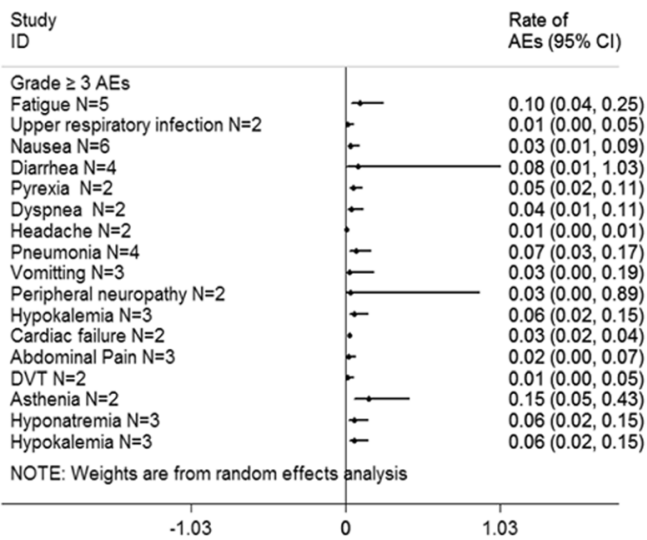

e ${ }_{10}^{\text {Study }}$ Grade 23 AEs Fatigue $\mathrm{N}=2$
Nausea $\mathrm{N}=2$ Hyperglycemia $\mathrm{N}=2$ Insomnia $\mathrm{N}=2$ Vomitting $\mathrm{N}=2$ Headache $\mathrm{N}=2$ Peripheral neuropathy $\mathrm{N}=2$ Pneumonia $\mathrm{N}=2$ Hypokalemia $\mathrm{N}$ Dyspnea $\mathrm{N}=2$
Peripheral edema $\mathrm{N}=3$
Constipation $\mathrm{N}=4$ Constipation
Cough $\mathrm{N}=3$ Muscle spasms $\mathrm{N}=2$ Pyrexia $\mathrm{N}=4$ Pyrexia $\mathrm{N}=4$
Back Pain $\mathrm{N}=2$ Asthenia $\mathrm{N}=2$
Diarrhea $\mathrm{N}=2$ NOTE: Weights are from random effects analysis

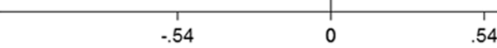

b

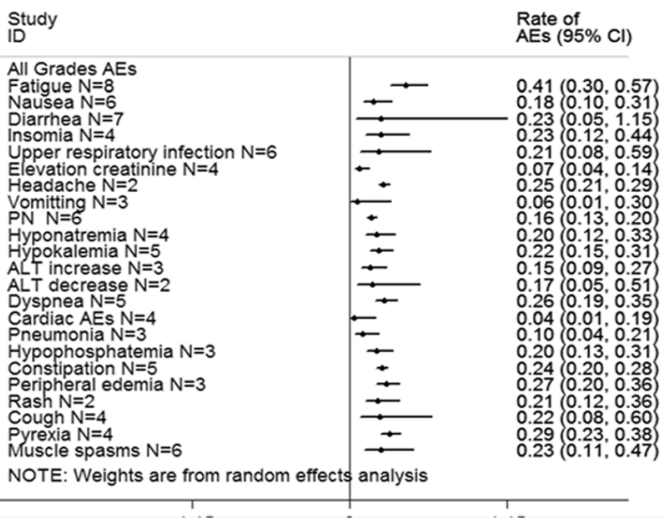

d Study Rate of ID AEs $(95 \% \mathrm{Cl})$

All Grades AEs Fatigue $\mathrm{N}=4$

Upper respiratory tract infection $\mathrm{N}=2$ Nausea $\mathrm{N}=5$ Diarrhea $\mathrm{N}=4$ Pyrexia $\mathrm{N}=2$ Headache $\mathrm{N}=2$ Pneumonia $\mathrm{N}=3$ Vomitting $\mathrm{N}=2$ Peripheral neuropathy $\mathrm{N}=2$ Hypokalemia $\mathrm{N}=3$ Constipation $\mathrm{N}=3$ Abdominal Pain $\mathrm{N}=3$ NOTE: Weights are from random effects analysis

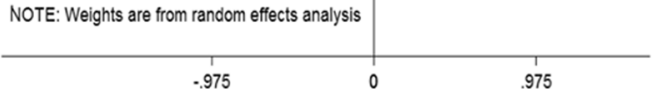

\section{f} Stud

All Grades $\mathrm{AEs}$
Fatigue $\mathrm{N}=4$
Nausea $\mathrm{N}=3$
Diarrhea $\mathrm{N}=3$
Pyrexia $\mathrm{N}=4$
Cough $\mathrm{N}=3$
Insomnia $\mathrm{N}=4$
Pneumonia $\mathrm{N}=2$
Vomitting $\mathrm{N}=2$
Hyperglycemia $\mathrm{N}=2$

Fig. 3 Meta-analysis of nonhematologic adverse events (AEs) with variable carfilzomib/panobinostat/elotuzumab-containing combination regimens in patients with multiple myeloma. $\mathbf{a} \geq$ Grade 3 nonhematologic AEs with carfilzomib combination regimens in patients with relapsed and refractory multiple myeloma. b All grades nonhematologic AEs with carfilzomib combination regimens in patients with relapsed and refractory multiple myeloma. $\mathbf{c} \geq$ Grade 3 nonhematologic AEs with panobinostat combination regimens in patients with relapsed and refractory multiple myeloma. $\mathbf{d}$ All grades nonhematologic AEs panobinostat combination regimens in patients with relapsed and refractory multiple myeloma. e $\geq$ Grade 3 nonhematologic AEs with elotuzumab combination regimens in patients with relapsed and refractory multiple myeloma. $\mathbf{f}$ All grades nonhematologic AEs with elotuzumab combination regimens in patients with relapsed and refractory multiple myeloma. $\mathrm{N}$ number of the included trials, Cl 95 \% confidence interval, Random random effects model 


\section{Acknowledgements}

We are indebted to Yanhua Sun for assistance with data analysis and critiquing the manuscript.

\section{Funding}

The authors did not receive any financial support.

\section{Availability of data and materials}

This analysis is a meta-analysis which overview and extracted data from previous published papers. These enrolled trials were shown in Table 1. All these papers can be found on-line.

\section{Authors' contributions}

LW participated in the design of the study and performed the statistical analysis. NZ performed the statistical analysis. WX collected the data. ZS helped to draft the manuscript. LL drafted the manuscript. All authors read and approved the final manuscript.

\section{Competing interests}

The authors declare that they have no competing interests.

\section{Consent for publication}

Not applicable.

\section{Ethics approval and consent to participate}

This pooled analysis was approved by the institutional review boards of Weifang People's Hospital, in accordance with the Helsinki Declaration.

\section{Author details}

'Department of Hematology, Weifang People's Hospital, Weifang, China.

${ }^{2}$ E.N.T. Department, Weifang People's Hospital, Weifang, China.

Received: 20 April 2016 Accepted: 7 July 2016

\section{Published online: 12 July 2016}

\section{References}

1. Kumar SK, Therneau TM, Gertz MA, et al. Clinical course of patients with relapsed multiple myeloma. Mayo Clin Proc. 2004;79(7):867-74.

2. Demo SD, Kirk CJ, Aujay MA, et al. Antitumor activity of PR-171, a novel irreversible inhibitor of the proteasome. Cancer Res. 2007;67(13):6383-91.

3. Atadja P. Development of the pan-DAC inhibitor panobinostat (LBH589): successes and challenges. Cancer Lett. 2009;280:233-41.

4. Hsi ED, Steinle R, Balasa B, et al. CS1, a potential new therapeutic antibody target for the treatment of multiple myeloma. Clin Cancer Res. 2008;14:2775-84.

5. Berdeja JG, Hart LL, Mace JR, Arrowsmith ER, Essell JH, Owera RS, Hainsworth JD, Flinn IW. Phase I/II study of the combination of panobinostat and carfilzomib in patients with relapsed/refractory multiple myeloma. Haematologica. 2015;100(5):670-6.

6. Shah JJ, Stadtmauer EA, Abonour R, Cohen AD, Bensinger WI, Gasparetto C, Kaufman JL, Lentzsch S, Vogl DT, Gomes CL, Pascucci N, Smith DD, Orlowski RZ, Durie BG. Carfilzomib, pomalidomide, and dexamethasone for relapsed or refractory myeloma. Blood. 2015;126(20):2284-90.

7. Berenson JR, Hilger JD, Yellin O, Dichmann R, Patel-Donnelly D, Boccia RV, Bessudo A, Stampleman L, Gravenor D, Eshaghian S, Nassir Y, Swift RA, Vescio RA. Replacement of bortezomib with carfilzomib for multiple myeloma patients progressing from bortezomib combination therapy. Leukemia. 2014;28(7):1529-36. 1.

8. Niesvizky R, Martin TG, Bensinger WI, Alsina M, Siegel DS, Kunkel LA, Wong AF, Lee S, Orlowski RZ, Wang M. Phase Ib dose-escalation study (PX-171-006) of carfilzomib, lenalidomide, and low-dose dexamethasone in relapsed or progressive multiple myeloma. Clin Cancer Res. 2013;19(8):248-56.

9. Papadopoulos KP, Siegel DS, Vesole DH, Lee P, Rosen ST, Zojwalla N, Holahan JR, Lee S, Wang Z, Badros A. Phase I study of 30-minute infusion of carfilzomib as single agent or in combination with low-dose dexamethasone in patients with relapsed and/or refractory multiple myeloma. J Clin Oncol. 2015;33((7):732-9.

10. Stewart AK, Rajkumar SV, Dimopoulos MA, Masszi T, Oriol A, Hájek R, Rosiñol L, Siegel DS, Mihaylov GG, Goranova-Marinova V, Rajnics P, Suvorov A, Niesvizky R, Jakubowiak AJ, San-Miguel JF, Ludwig H, Wang M, Maisnar V, Minarik J, Bensinger WI, Mateos MV, Ben-Yehuda D, Kukreti V,
Zojwalla N, Tonda ME, Yang X, Xing B, Moreau P, Palumbo A. Carfilzomib, lenalidomide, and dexamethasone for relapsed multiple myeloma. N Engl J Med. 2015;372(2):14-52.

11. Wang M, Martin T, Bensinger W, Alsina M, Siegel DS, Kavalerchik E, Huang M, Orlowski RZ, Niesvizky R. Phase 2 dose-expansion study (PX-171-006) of carfilzomib, lenalidomide, and low-dose dexamethasone in relapsed or progressive multiple myeloma. Blood. 2013;122(18):3122-8.

12. Berenson JR, Klein $L M$, Rifkin $R M$, et al. Results of the dose-escalation portion of a phase $1 / 2$ study (CHAMPION-1) investigating weekly carfilzomib in combination with dexamethasone for patients with relapsed or refractory multiple myeloma. J Clin Oncol. 2014;32(Suppl):8594. abstract. (2).

13. Dimopoulos MA, Philippe M, Antonio P, Joshua DE, Ludek P, Roman H, et al. Carfilzomib and dexamethasone (Kd) vs bortezomib and dexamethasone (Vd) in patients (pts) with relapsed multiple myeloma (RMM): results from the phase III study ENDEAVOR. J Clin Oncol. 2015;33:suppl; abstr 8509.

14. Kaufman J, Zimmerman T, Jakubowiak A, et al. Phase I study of the combination of carfilzomib and panobinostat for patients with relapsed and refractory myeloma: a multicenter MMRC clinical trial [abstract]. Haematologica. 2013;98 suppl 1:Abstract 322.

15. Vesole DH, Bilotti E, Richter JR, McNeill A, McBride L, Raucci L, Anand P, Bednarz U, Ivanovski K, Smith J, Batra V, Aleman A, Sims T, Guerrero L, Mato A, Siegel DS. Phase I study of carfilzomib, lenalidomide, vorinostat, and dexamethasone in patients with relapsed and/or refractory multiple myeloma. Br J Haematol. 2015;171(1):52-9.

16. Offidani M, Polloni C, Cavallo F, Liberati AM, Ballanti S, Pulini S, Catarini M, Alesiani F, Corvatta L, Gentili S, Caraffa P, Boccadoro M, Leoni P, Palumbo A. Phase II study of melphalan, thalidomide and prednisone combined with oral panobinostat in patients with relapsed/refractory multiple myeloma. Leuk Lymphoma. 2012;53(9):1722-7.

17. Richardson $P G$, Schlossman RL, Alsina M, Weber DM, Coutre $S E$, Gasparetto C, Mukhopadhyay S, Ondovik MS, Khan M, Paley CS, Lonial S. PANORAMA 2: panobinostat in combination with bortezomib and dexamethasone in patients with relapsed and bortezomib-refractory myeloma. Blood. 2013;122(14):2331-7.

18. San-Miguel JF, Richardson PG, Günther $A$, Sezer $O$, Siegel $D$, Bladé J, LeBlanc R, Sutherland H, Sopala M, Mishra KK, Mu S, Bourquelot PM, Victoria Mateos M, Anderson KC. Phase lb study of panobinostat and bortezomib in relapsed or relapsed and refractory multiple myeloma. J Clin Oncol. 2013;31(29):3696-703.

19. Berenson JR, Hilger JD, Yellin O, Boccia RV, Matous J, Dressler K, Ghazal HH, Jamshed S, Kingsley EC, Harb WA, Noga SJ, Nassir Y, Swift RA, Vescio R. A phase 1/2 study of oral panobinostat combined with melphalan for patients with relapsed or refractory multiple myeloma. Ann Hematol. 2014;93(1):89-98.

20. San-Miguel JF, Hungria VT, Yoon SS, Beksac M, Dimopoulos MA, Elghandour A. Panobinostat plus bortezomib and dexamethasone versus placebo plus bortezomib and dexamethasone in patients with relapsed or relapsed and refractory multiple myeloma: a multicentre, randomised, double-blind phase 3 trial. Lancet Oncol. 2014;15(11):1195-206.

21. Jakubowiak AJ, Benson DM, Bensinger W, Siegel DS, Zimmerman TM, Mohrbacher A, Richardson PG, Afar DE, Singhal AK, Anderson KC. Phase I trial of anti-CS1 monoclonal antibody elotuzumab in combination with bortezomib in the treatment of relapsed/refractory multiple myeloma. J Clin Oncol. 2012;30(16):1960-5.

22. Lonial S, Vij R, Harousseau JL, Facon T, Moreau P, Mazumder A, Kaufman JL, Leleu X, Tsao LC, Westland C, Singhal AK, Jagannath S. Elotuzumab in combination with lenalidomide and low-dose dexamethasone in relapsed or refractory multiple myeloma. J Clin Oncol. 2012;30(16):1953-9.

23. Lonial S, Dimopoulos M, Palumbo A, White D, Grosicki S, Spicka I, et al. Elotuzumab therapy for relapsed or refractory multiple myeloma. N Engl J Med. 2015;373(7):621-31

24. Richardson PG, Jagannath S, Moreau P, Jakubowiak AJ, Raab MS, Facon T, et al. Elotuzumab in combination with lenalidomide and dexamethasone in patients with relapsed multiple myeloma: final phase 2 results from the randomised, open-label, phase 1b-2 dose-escalation study. Lancet Haematol. 2015;2(12):e516-27.

25. Kumar SK, Lee JH, Lahuerta JJ, International Myeloma Working Group, et al. Risk of progression and survival in multiple myeloma relapsing after therapy with IMiDs and bortezomib: a multicenter international myeloma working group study. Leukemia. 2012;26(1):149-57. 
26. Dimopoulos M, Spencer A, Attal M, Prince HM, Harousseau JL, Dmoszynska A, et al. Lenalidomide plus dexamethasone for relapsed or refractory multiple myeloma. N Engl J Med. 2007;357(21):2123-32.

27. Weber DM, Chen C, Niesvizky R, Wang M, Belch A, Stadtmauer EA, et al.

Lenalidomide plus dexamethasone for relapsed multiple myeloma in North America. N Engl J Med. 2007;357(21):2133-42.

Submit your next manuscript to BioMed Central and we will help you at every step:

- We accept pre-submission inquiries

- Our selector tool helps you to find the most relevant journal

- We provide round the clock customer support

- Convenient online submission

- Thorough peer review

- Inclusion in PubMed and all major indexing services

- Maximum visibility for your research

Submit your manuscript at www.biomedcentral.com/submit 